\title{
GEORREFERENCIAMENTO DA BASE DE DADOS DA DEFESA CIVIL DO MUNICÍPIO DE JACAREÍ/SP
}

\author{
DOI 10.37619/issn2447-5378.v7i1.307.72-81 \\ V.R. Cardozo ${ }^{1, *}$; C.A.A. Torres ${ }^{2}$; A.F. Souza ${ }^{1}$ \\ 1 Faculdade de Tecnologia Professor Francisco de Moura - FATEC Jacareí \\ Av. Faria Lima, 155 - Jardim Santa Maria, Jacareí/SP, \\ CEP.: 12328-070, Brasil. \\ Telefone: (12) 3953-7926 \\ 2 Defesa Civil de Jacareí \\ Praça Luís Sipúlio Filho, 57 - Parque Santo Antônio, Jacareí/SP, \\ CEP.: 12309-380, Brasil. \\ Telefone: (12) 3952-4006 \\ *vrcardozzo@gmail.com
}

\begin{abstract}
RESUMO: A Defesa Civil é um órgão voltado para o atendimento da sociedade em situação de risco a vida. Para prestar um bom serviço, a Defesa Civil precisa ter informações dos locais susceptíveis a cada tipo de risco, para assim poder planejar ações proativas e reativas. Para fazer um bom planejamento, é necessário ter uma base de dados digital e ferramentas capazes de extrair informações dos registros. Como os dados possuem características espaciais, então organizá-los num ambiente de Sistema de Informações Geográficas torna possível fazer operações utilizando a geolocalização dos eventos. O objetivo desse trabalho é descrever o processo de levantamento, compilação e georreferenciamento da base de dados de deslizamentos, alagamentos, inundações, queimadas e da Represa de Jaguari da Defesa Civil do município de Jacareí/SP.
\end{abstract}

PALAVRAS-CHAVE: georreferenciamento; defesa civil; geotecnologias.

ABSTRACT: The Civil Defense is an agency whose aim is to serve the society in situations in which their lives are at risk. So as for the Civil Defense to provide a good service, it needs to have information concerning the places which are susceptible to each type of risk, in order to come up with proactive and reaction plans. A good plan calls for a digital database and tools that enable us to extract information from the registries. As the data have spatial features, it is possible to organize them in a Geographic Information System and carry out operations using event geolocation. The objective of this work is to describe the data collection, compilation and georeferencing process from the database of landslides, floods, fires, and the Jaguari Dam that belongs to the Civil Defense of the town of Jacareí.

KEYWORDS: georeferencing; civil defense; geotechnologies.

\section{INTRODUÇÃO}

A Defesa Civil é um órgão social voltado para autodefesa e proteção do cidadão, utilizando-se de meios de preparação, prevenção, mitigação e recuperação para realizar a proteção e defesa da 


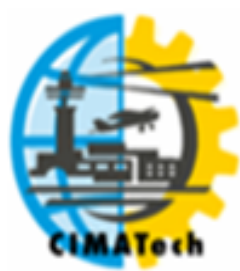

sociedade, a fim de estabelecer a normalidade social. Hoje em dia as principais atividades de uma Defesa Civil estão voltadas para as áreas de risco (DEFESA CIVIL DO ESTADO DE SÃO PAULO, 2020).

As áreas de risco são locais onde não é recomendada a construção de casas ou instalações, pelo fato delas ficarem expostas a ocorrências de desastres naturais recorrentes, sendo os principais inundações em margens de rios e deslizamento em áreas de encostas no período chuvoso e fogo em mato em períodos de estiagem (ALVES et al., 2019).

A partir da promulgação da Lei Nacional $n^{\circ} 12.608$ de 2012 - que dispõe sobre o Sistema Nacional de Proteção e Defesa Civil e que institui a Política Nacional de Proteção e Defesa Civil (PNPDEC), a Defesa Civil no país abandonou a prática de só agir depois da ocorrência de desastres e passou a estimular a ação proativa de agir antes da ocorrência dos eventos (FERREIRA, 2014).

A Defesa Civil precisa ter um planejamento para agir antes, durante e após os desastres. $\mathrm{O}$ planejamento busca desenvolver as capacidades necessárias para o gerenciamento eficiente de todos os tipos de emergência e são parte disso as ações destinadas a reduzir a ocorrência e a intensidade de desastres por meio de: mapeamento de áreas de risco; construção de obras de contenção e correção; e capacitação da sociedade (DEFESA CIVIL DO ESTADO DO MATO GROSSO, 2020).

Dada a maior frequência de eventos severos, como chuvas intensas e inundações causadas pelas mudanças climáticas (COLL, 2020), tem-se um cenário de ameaça conjugada com o aumento das vulnerabilidades causadas pelas ocupações irregulares de áreas susceptíveis a alagamentos e inundações e o pouco investimento nas capacidades locais (FERREIRA, 2014).

Segundo relatado por Vestana (2008) a inundação é o desastre mais recorrente nas áreas urbanizadas do país nas últimas décadas, e Oliveira \& Silva (2019) mapearam as áreas de risco a inundação no município de Rio Grande da Serra/SP e consideraram que as variáveis mais relevantes para ocorrência das inundações são: declividade do terreno, hipsometria, relevo, cobertura vegetal, capacidade de drenagem do solo, bem como uso e manejo inadequado da terra e o grau de impermeabilização do solo.

Além das inundações e alagamentos causados por fenômenos naturais, a Defesa Civil precisa lidar com os riscos de queimadas, deslizamentos, inundação causadas pelo rompimento de barragens etc. Portanto, é importante ter uma base de dados digital para cruzamentos e análises das variáveis influenciadoras nos desastres. Como os riscos causados pelas queimadas, inundações, alagamentos e deslizamentos só são conhecidos estudando toda a área envolvida no evento, então tem-se que o georreferenciamento da base dados se torna uma ferramenta relevante na análise dos dados e na tomada de decisões de uma Defesa Civil.

Oliveira \& Silva (2019) destacam que o mapeamento e zoneamento das áreas de risco à inundação devem ser considerados na tomada de decisão dos gestores públicos, de modo que o risco a desastres naturais deve ser considerado na elaboração e aprovação do Plano Diretor e levado em consideração quando o poder público deseja ampliar o perímetro urbano.

Pfaltzgraff (2007) destaca a importância de o poder público dispor de ferramentas eficazes para localizar as áreas naturalmente suscetíveis a deslizamentos, tanto ocupadas como aquelas ainda livres de ocupação. Para diminuir os custos com o levantamento e manutenção da base de dados o autor sugere o uso de técnicas e ferramentas de geoprocessamento e sensoriamento remoto.

Machado et al. (2014) destaca que o estabelecimento de políticas de prevenção de queimadas urbanas pode ser definido a partir de estudos sobre suas causas. As queimadas urbanas são agravadas por condições meteorológicas, tais como, a falta de precipitação, elevada velocidade do vento e baixa umidade relativa do ar, além de estarem relacionadas com atividades humanas. Nesse estudo os 


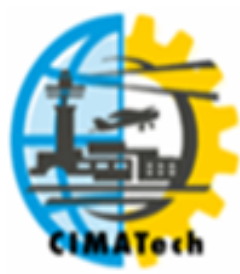

ISSN 2447-5378

autores utilizaram técnicas e ferramentas de geoprocessamento para manusear imagens de satélites e as ocorrências de queimadas do Corpo de Bombeiros de Cuiabá/MT.

O objetivo desse trabalho é descrever o processo de levantamento, compilação e georreferenciamento da base de dados da Defesa Civil do município de Jacareí/SP com vista para a disponibilização de dados para o munícipe e, principalmente, auxiliar na gestão e na tomada de decisões pelo poder público.

\section{MATERIAIS E MÉTODOS}

\subsection{Caracterização da área de estudo}

O município de Jacareí está localizado no Estado de São Paulo, na Região Metropolitana do Vale do Paraíba e Litoral Norte, fazendo fronteira com os municípios de São José dos Campos, Jambeiro, Santa Branca, Guararema, Santa Isabel e Igaratá. Segundo dados do IBGE para o ano de 2020, o município possuía uma população estimada em 235.416 habitantes, com uma área total de 464,272 km², e uma densidade demográfica de cerca de 454,94 hab./km² (IBGE, 2020b).

A cidade é cortada pelo Rio Paraíba do Sul e alguns córregos. A Figura 1 mostra a área urbanizada do município sobre um MDS (Modelo Digital de Superfície), onde cada pixel possui a altura em relação ao nível do mar, a elevação varia de 506 a 833 m. Essa imagem foi fornecida pela Prefeitura Municipal de Jacareí e a resolução espacial é de $5 \times 5 \mathrm{~m}$. A área urbanizada foi obtida em IBGE (2020a) e corresponde aos dados de 2015. Observa-se que a cidade se encontra majoritariamente numa planície.

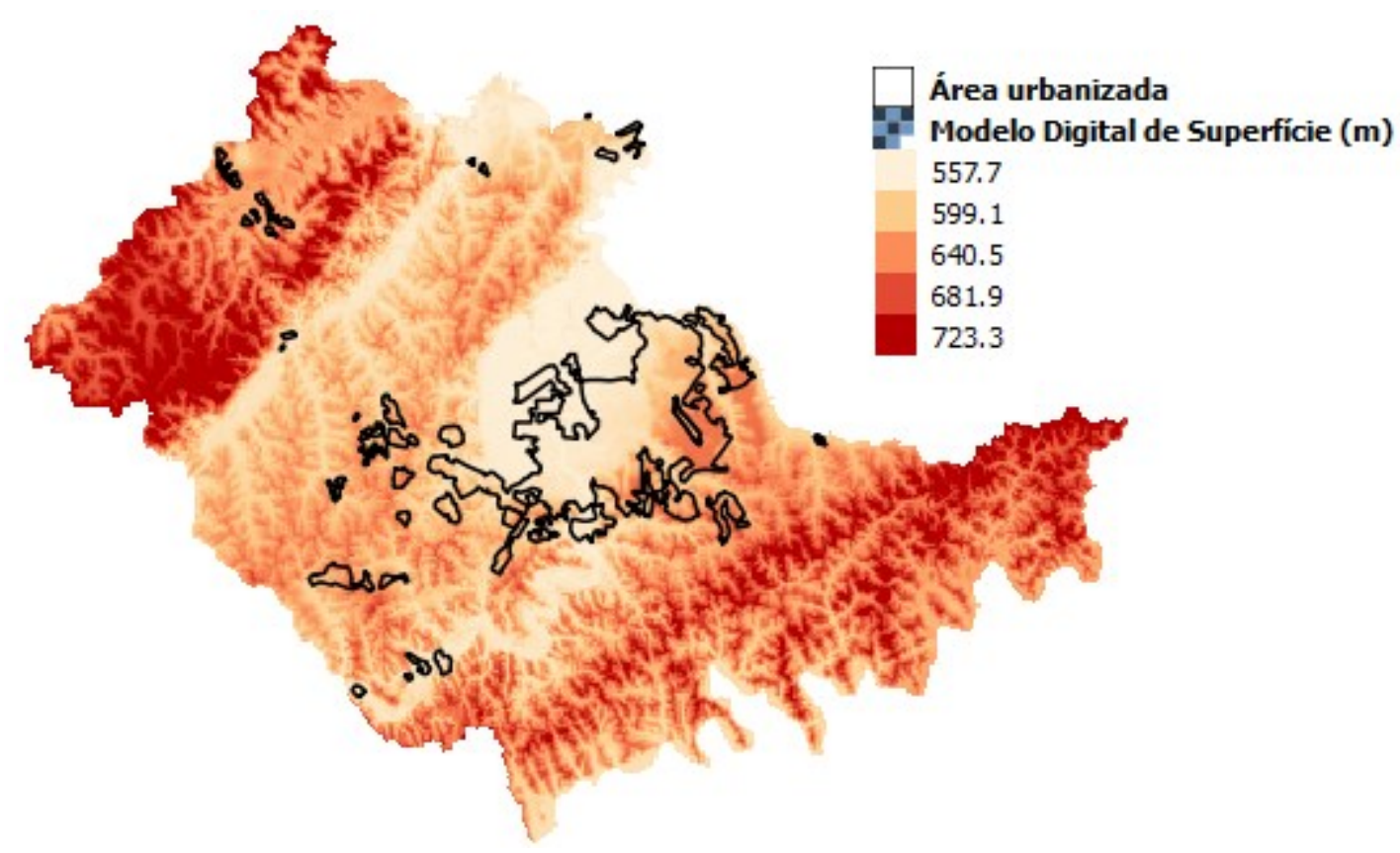

Figura 1. Modelo Digital de Superfície e área urbanizada do Município de Jacareí.

\subsection{Base de dados}

Os dados da Defesa Civil de Jacareí possuem as seguintes origens:

- Deslizamentos: foram extraídos dos relatórios do plano de erradicação de áreas de risco elaborados pelo IPT (Instituto de Pesquisas Tecnológicas). A confecção desse relatório 


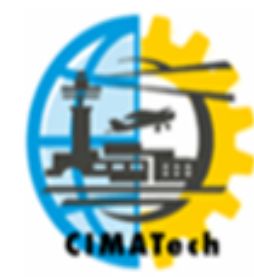

ocorreu a partir das áreas propícias a deslizamentos apresentadas pela Defesa Civil para os geólogos do IPT para classificarem o grau de risco de cada uma dessas áreas;

- Alagamento e inundação: são baseados nos históricos de ocorrências atendidas pela Defesa Civil, onde as áreas de risco de alagamento e inundação são aquelas com maior incidência e que ainda não tiveram obras para resolver o problema;

- Queimada: as áreas de risco de fogo em mato foram levantadas a partir das ocorrências do Corpo de Bombeiros, serviço de atendimento de emergência da Defesa Civil e, recentemente, através das câmeras de monitoramento operadas pelos agentes da secretaria de segurança;

- Demais ocorrências: queda de árvores, danos estruturais em imóveis etc. são registradas pelo serviço de atendimento de emergência da Defesa Civil e algumas confirmadas em campo pela equipe nos relatórios de ocorrências;

- Represa de Jaguari: área inundável, rotas de fuga e pontos de encontro da Defesa Civil em caso de rompimento da represa. A área inundável foi fornecida pela CESP (Companhia Energética de São Paulo) e os dados de rotas de fuga e pontos de encontro foram elaborados pela Defesa Civil.

Os relatórios de ocorrência são feitos em prancheta, por um agente da Defesa Civil presente no local de atendimento da ocorrência de deslizamento, alagamento, inundação, queimada etc. Os registros nesses relatórios constituem a base de dados da Defesa Civil e possuem informações relevantes para definir ações de prevenção, recuperação, preparação e emergência. É através do relatório de ocorrências que o gestor tem uma visão do tipo de problema e sua magnitude, possibilitando assim uma tomada de decisão mais eficaz.

Os caminhos do relatório de ocorrência são diversos. Dependem do tipo de ocorrência, por exemplo: queda de árvore, problemas com córregos e rios, recolhimento de entulhos, são encaminhados a secretaria de meio ambiente, já os serviços de recuperação de vias danificadas são encaminhados a secretaria de infraestrutura, os problemas com tubulações de água e esgoto são encaminhados ao SAAE (Serviço Autônomo de Água e Esgoto) e queimadas vai para a posturas e meio ambiente.

\subsection{Processamento de dados}

Segundo observações dos próprios autores, notou-se que os dados de ocorrência de campo da Defesa Civil estavam em relatórios de papel e arquivos Word, isto é, não existiam dados tabulados. Primeiramente fez-se a digitação/transposição desses dados num formato tabular e, na sequência, fezse a geolocalização dos endereços para atribuir coordenadas geográficas para cada ocorrência.

Como alguns endereços estavam incompletos ou desatualizados, então teve-se de fazer manualmente a geolocalização utilizando o QGIS 2.18.28 com imagens de fundo do Google Satélite e Google Rodoviário obtidos através do complemento QuickMapServices para QGIS. Ao final desse processo obteve-se um shapefile com as localizações, tipos de ocorrência, data e demais dados da ocorrência.

Os dados oriundos do Corpo de Bombeiros já estavam tabulados, mesmo assim foi necessário realizar a geolocalização manualmente para garantir a consistência dos endereços.

A área inundável da Represa de Jaguari e as áreas de deslizamentos já estavam em shapefile, mas os dados de alagamentos estavam dispersos em relatórios de papel e arquivos KML. No caso dos arquivos de papel foi necessária a ajuda do técnico da Defesa Civil para delimitar as áreas usando o QGIS e as imagens de fundo do Google Satélite. O mesmo procedimento foi utilizado para vetorizar as rotas de fuga e pontos de encontro da Defesa Civil no caso de rompimento da Represa de Jaguari. 
Alguns dados não possuíam um endereço conhecido, pois não estavam associados a um logradouro, então precisou-se fazer trabalhos de campo com GPS para levantamento das localizações.

Cada tipo de dado mapeado (alagamento, deslizamento etc.) foi agrupado numa tabela do SGBD (Sistema Gerenciador de Banco de Dados) PostgreSQL. A organização dos dados em tabelas permite fazer o cruzamento de dados através de operações espaciais e visualizar os resultados no QGIS.

\section{RESULTADOS E DISCUSSÃO}

A vetorização dos dados e integração deles num SGBD espacial expande a capacidade da Defesa Civil de gerar informações e planejar a tomada de decisões. A seguir são apresentadas algumas operações e análises.

\subsection{Dados da Represa de Jaguari}

Em caso de rompimento da Represa de Jaguari, a área inundável no município de Jacareí é de 1137,95 ha, sendo que 4,24 ha estão em áreas consideradas urbanizadas. Essas informações foram obtidas fazendo a operação espacial de interseção e posterior cálculo da área utilizando as funções da extensão espacial PostGIS (extensão espacial para o SGBD PostgreSQL).

De posse das informações visuais no mapa (Figura 2) os técnicos da Defesa Civil foram capazes de mapear as rotas de fuga e os pontos de encontro levando em consideração a área inundada e as estradas oficiais do município.

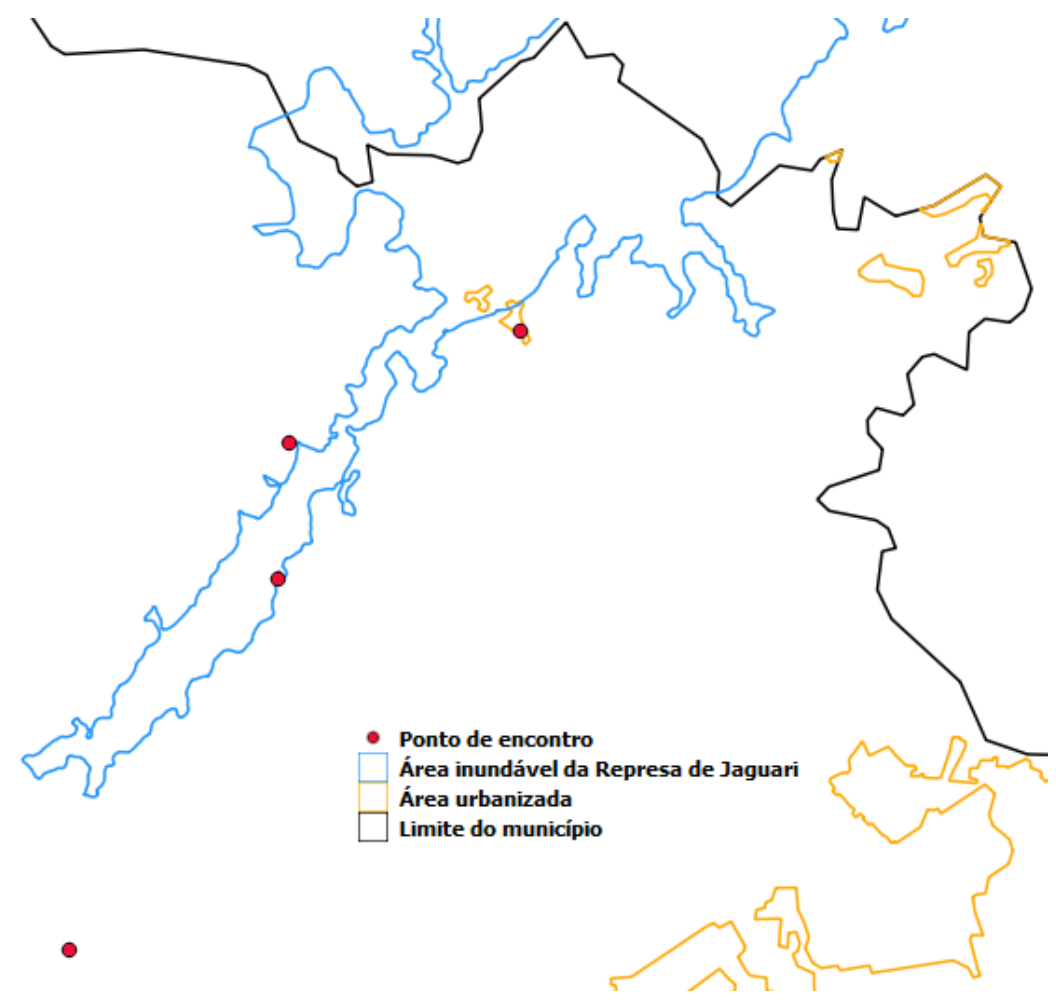

Figura 2. Dados da Represa de Jaguari. 


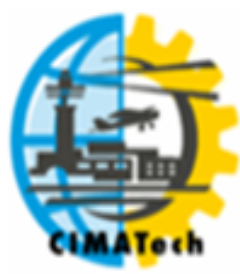
Technology

\section{ISSN $2447-5378$}

Utilizando as imagens do Google Satélite seria possível mapear as residências na área inundável e fazer um plano de evacuação levando em conta o tempo de progressão da frente d'água e a distribuição espacial das residências.

\subsection{Dados de queimadas}

Foram georreferenciados os focos de queimada de 2019 e 2020 do Corpo de Bombeiros e de 2020 da Defesa Civil. A sobreposição dos dados de queimada com outros dados espaciais, tais como, área urbanizada e imagens do Google Satélite ajudam a perceber tendências de locais propícios a ocorrência de queimadas urbanas. Observando o mapa da Figura 3 é possível perceber que a maioria dos focos estão na periferia da cidade, assim como destacado por Machado et al. (2014). Porém com as imagens em alta resolução do Google Satélite os técnicos da Defesa Civil podem identificar os lotes vazios nessas áreas mais propícias a ocorrência de queimadas e notificar os proprietários para fazer a limpeza no período de seca.

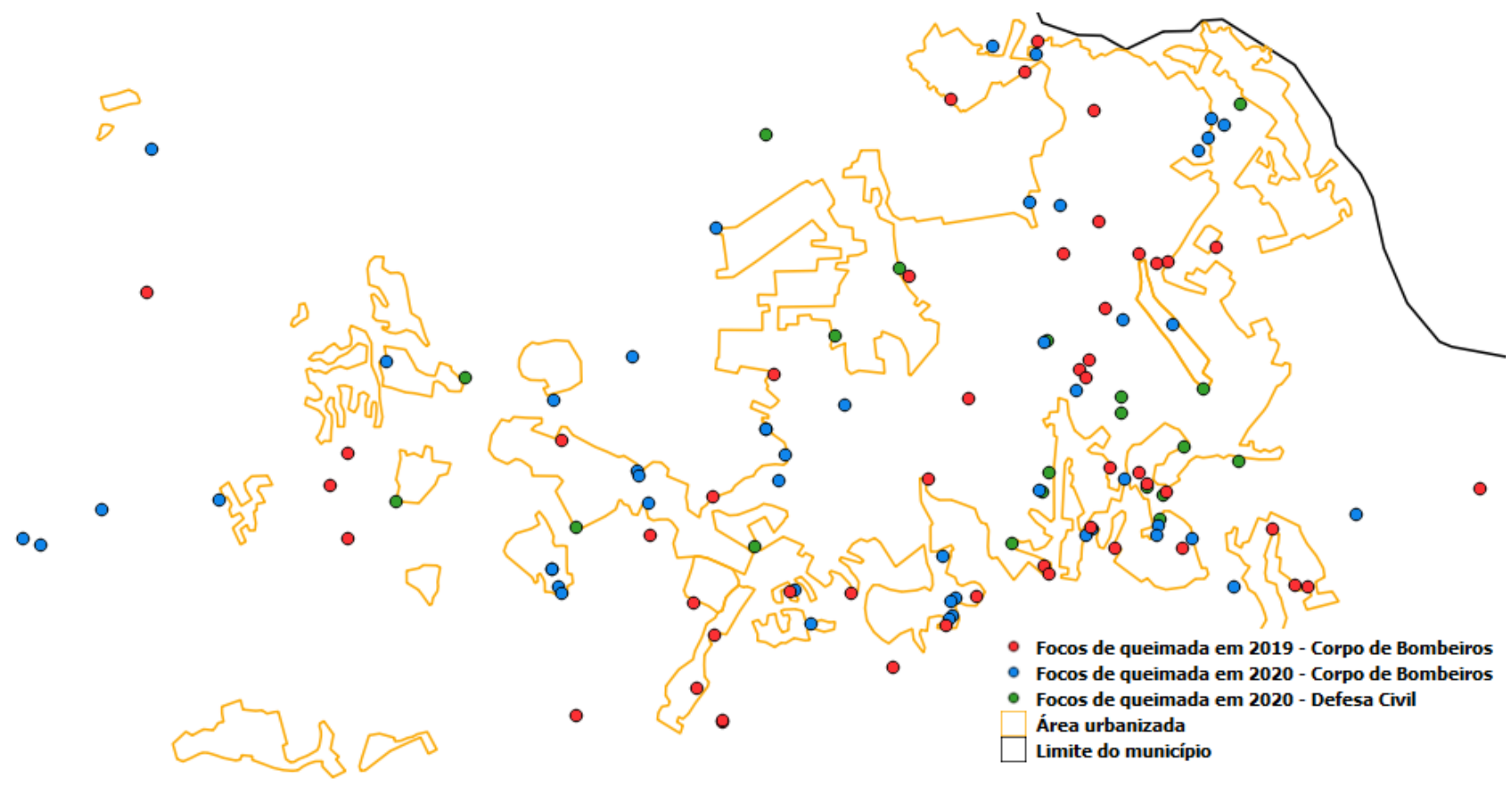

Figura 3. Focos de queimada.

Por enquanto a base de dados possui poucos focos de queimada, mas, com o passar dos anos a quantidade poderá aumentar, daí os técnicos podem usar a ferramenta de mapa de calor para destacar as áreas do município com maior ocorrência de focos. Esse tipo de recurso está disponível nos SIGs (Sistema de Informação Geográfica), assim como o QGIS.

\subsection{Dados de alagamentos e inundações}

Atualmente existem $24,8 \mathrm{~km}$ de vias com risco de alagamento e inundação (Figura 4). Como a possibilidade de alagamento está condicionada ao volume de chuva, então é possível cruzar os dados de elevação - disponível numa imagem de MDS da Prefeitura de Jacareí - e determinar o volume de chuva necessária para alagar cada trecho dessas vias. Neste momento, este tipo de estudo só está 


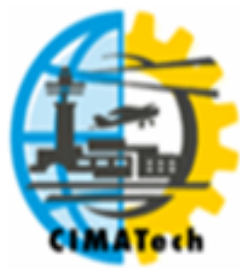
Technology

ISSN 2447-5378

disponível em um ambiente de SIG, pois existe a necessidade de operar dados vetoriais (vias urbanas) e matriciais (imagem de elevação, onde cada pixel possui a altura em relação ao nível do mar).

Fazendo um fatiamento das elevações (MDS) é possível criar curvas de nível e assim é possível determinar a área influenciada pelo alagamento e inundação, e posteriormente usando as imagens do Google Satélite é possível contar a quantidade de residências que poderão ser atingidas em cada volume de chuva e nível do rio/córrego, respectivamente.

\subsection{Dados de deslizamentos}

Atualmente existem 24 áreas com risco de deslizamentos (Figura 4). Como os deslizamentos são importantes se eles oferecerem risco a vida, então com o uso das imagens do Google Satélite é possível mapear as residências que estão nas áreas susceptíveis a deslizamentos. Esse tipo de levantamento pode ser útil para orientar a gestão municipal e decidir sobre investimentos nessas áreas.

Usando imagens de satélites e até mesmo as imagens do Google Satélite é possível mapear as áreas verdes que influenciam nas áreas de risco e assim a Defesa Civil pode orientar o poder público a tomar medidas de contenção.

\subsection{Demais dados de ocorrência da Defesa Civil}

A Defesa Civil recebe o chamado para atender ocorrências de diversos tipos, tais como, quedas de árvores, quedas de muros, trincas em casas, avarias em telhados, animais silvestres, apoio a equipe da Assistência Social, SAAE e bombeiros.

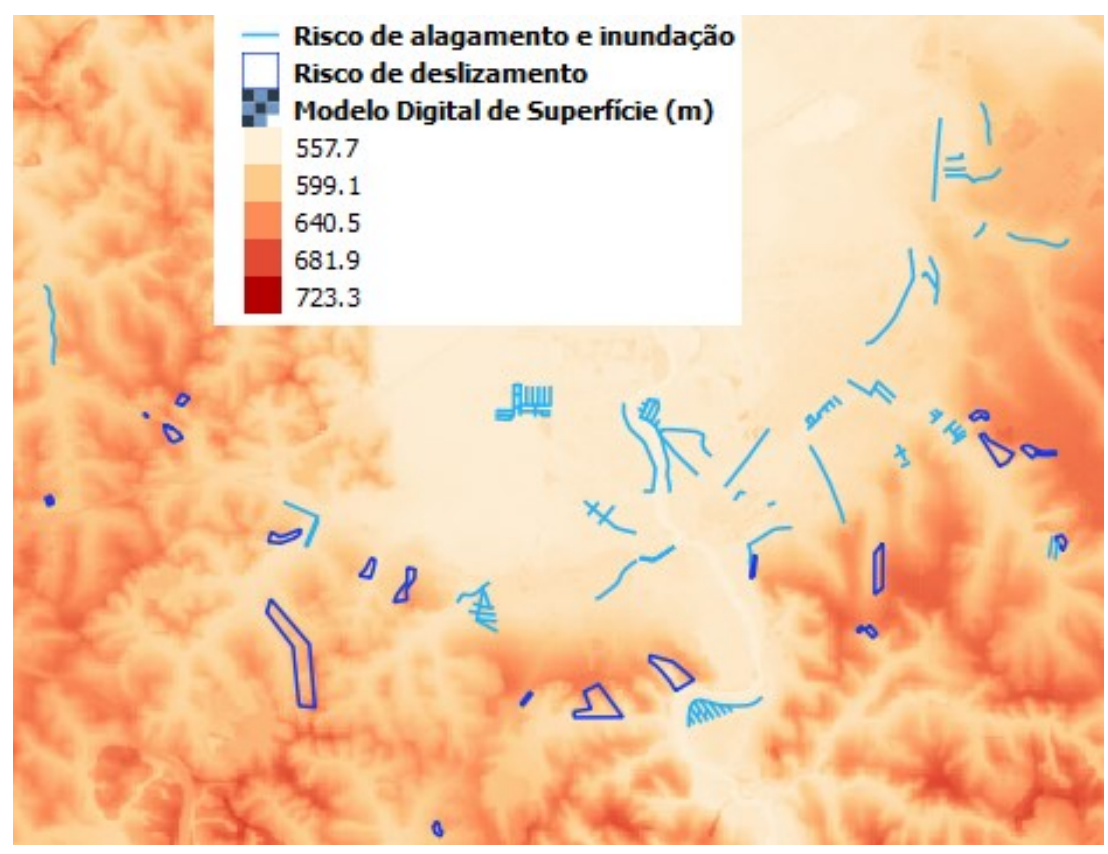

Figura 4. Áreas com risco de alagamento, inundação e deslizamento.

Foram georreferenciados os dados de ocorrências diversas entre os anos de 2017 a 2020 (Figura 5). O problema presente nesses dados, é que eles não possuem um padrão na nomeação das ocorrências, como exemplo, as ocorrências de quedas de árvores ocorrem de formas distintas. Para um operador humano é perfeitamente possível a interpretação de termos distintos, mas isso dificulta extrair estatísticas usando consultas em ambiente de banco de dados. 


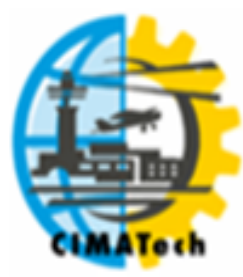

Quando comparadas as distribuições de ocorrências, percebe-se que os focos de queimada predominam na periferia (Figura 3), os alagamentos e deslizamentos ocorrem em áreas conhecidas (Figura 4), já as demais ocorrências ocorrem de forma distribuída pela cidade (Figura 5), visto que, geralmente, quedas de árvore ocorrem em áreas mais urbanizadas e problemas com os imóveis - a exemplo das residências que apresentam quedas de muros, trincas em casas, avarias em telhados -, ocorrem nas áreas menos assistidas pelo poder público.

\subsection{Disponibilização dos dados na internet}

A visualização de dados espaciais nos formatos de shapefile requer o uso de softwares específicos que necessitam de algum treinamento pelo usuário. Além de instalar os softwares no computador de cada usuário da Defesa Civil, seria necessário manter o banco de dados num computador com servidor Web, ou seja, essa máquina precisa operar com segurança e estar ligada o tempo todo. Por esses motivos, optou-se por carregar os dados na plataforma Here Studio e disponibilizar o acesso para os usuários da Defesa Civil. Apesar da plataforma oferecer apenas a visualização na versão gratuita, esse recurso atende às necessidades dos técnicos da Defesa Civil.

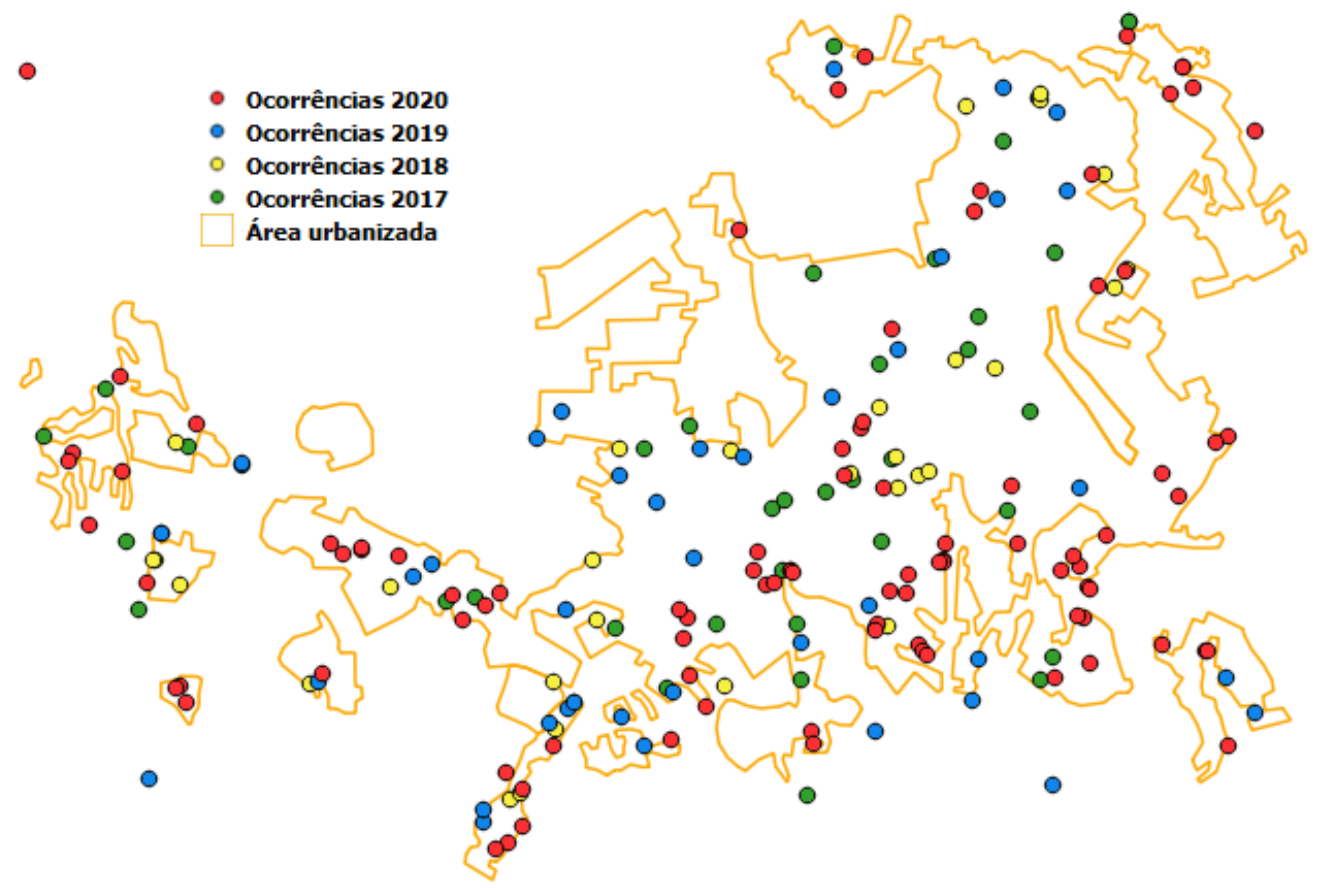

Figura 5. Pontos de atendimento da Defesa Civil.

\section{CONCLUSÃo}

Uma base de dados dispersa em arquivos de diferentes formatos dificulta a organização e o processamento para extrair informações. Além de inviabilizar o seu uso por um longo período, pois, geralmente, esses arquivos ficam distribuídos nos computadores de vários usuários e correm o risco de serem perdidos com facilidade no decorrer do tempo. Tendo em vista estes motivos e as ocorrências apresentadas no território de Jacareí, ressalta-se a importância em confeccionar uma base de dados normalizada e centralizada, operando num ambiente seguro e disponível para consultas, 


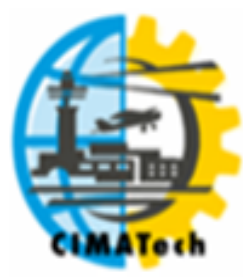

ISSN $2447-5378$

assim como em sistemas de banco de dados (SGBD). A existência dessas informações organizadas em banco de dados, permitirá que novas equipes da Defesa Civil tenham acesso de modo integrado aos dados.

Segundo observado pelos autores o processo de organização dos dados em tabelas de banco de dados ocorreu sem maiores dificuldades, em parte por conta do suporte dos técnicos da Defesa Civil. As maiores dificuldades ocorreram na geolocalização dos endereços das ocorrências, motivadas por endereços incompletos ou incoerentes. Notou-se que esses problemas foram causados em locais onde não existe uma definição clara do logradouro, típica de áreas ainda não regularizadas pelo poder público. Existiram problemas também com vias que mudaram de nome. Com a estrutura de armazenamento montada, cabe a equipe da Defesa Civil apenas alimentar a base de dados com as novas ocorrências usando as coordenadas geográficas, eliminando assim o risco de localizações incoerentes.

A manutenção da base de dados georreferenciada permite o uso de ferramentas de SIG para a realização de operações espaciais com os dados, bem como a extração de informações relevantes na tomada de decisões proativas e reativas pela Defesa Civil. Junta-se a isso a possibilidade de munir o poder público com uma visão mais detalhada e ampla da situação do município, viabilizando uma melhor realização das obras de contenção. Por fim, a disseminação de alguns desses dados na internet, permitirá ao cidadão ver as áreas de risco no mapa e evitar adquirir e construir em áreas de risco.

\section{AGRADECIMENTOS}

A Prefeitura Municipal de Jacareí por conceder a bolsa de estágio. A Defesa Civil do Município de Jacareí pela infraestrutura física e pelo suporte relacionado aos dados utilizados neste trabalho. Agradecemos também a Fatec de Jacareí pelo incentivo para o desenvolvimento de artigos e participação em projetos.

\section{REFERÊNCIAS}

ALVES, R. B.; KUHNEN, A.; CRUZ, R. M. Escala de apego à moradia em área de risco: construção e evidências baseadas no conteúdo. Saúde em Debate [online]. v. 43, n.spe3, pp. 137-151, 2019. Disponível em https://doi.org/10.1590/0103-11042019S310. Acesso em: $25 / 08 / 2020$.

COLL, L. A estreita relação entre mudanças climáticas e o aumento de eventos extremos. Jornal da UNICAMP. $2020 . \quad$ Disponível em https://www.unicamp.br/unicamp/ju/noticias/2020/02/27/estreita-relacao-entre-mudancasclimaticas-e-o-aumento-de-eventos-extremos. Acesso em: 13/09/2020.

DEFESA CIVIL DO ESTADO DE SÃO PAULO. Missões. Disponível em http://www.defesacivil.sp.gov.br/missoes. Acesso em: 24/08/2020.

DEFESA CIVIL DO ESTADO DO MATO GROSSO. O que é proteção e defesa civil. Disponível em http://www.defesacivil.mt.gov.br/o-que-e-protecao-e-defesa-civil. Acesso em: $13 / 09 / 2020$. 


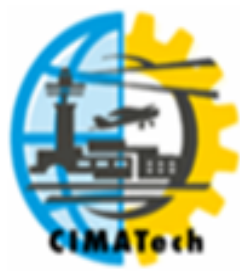

\section{Congress of Industrial}

Management and Aeronautical

FERREIRA, S. H. G. Primazia da gestão dos riscos: o novo paradigma da proteção e defesa civil. Revista Jurídica Consulex, Brasília-DF, , v. 421, 01 ago. 2014. Disponível em http://www.sidec.sp.gov.br/defesacivil/media/OSDownloads/1405725767_O\%20NOVO $\% 20$ PARADIGMA\%20DA\%20PROTECAO\%20E\%20DEFESA\%20CIVIL.pdf. Acesso em: $12 / 09 / 2020$.

IBGE. Áreas urbanizadas do Brasil. Disponível em

ftp://geoftp.ibge.gov.br/organizacao_do territorio/tipologias_do territorio/areas urbanizadas_do_b rasil/2015/Shape/. Acesso em 16/10/2020.

IBGE. Cidades e Estados. Disponível em https://www.ibge.gov.br/cidades-eestados/sp/jacarei.html. Acesso em: 16/10/2020.

MACHADO, N. G.; SILVA, F. C. P.; BIUDES, M. S. Efeito das condições meteorológicas sobre o risco de incêndio e o número de queimadas urbanas e focos de calor em Cuiabá-MT, Brasil. Ciência e Natura, Santa Maria, v. 36 n. 3 set-dez. 2014, p. 459 - 469. Disponível em https://www.redalyc.org/pdf/4675/467546174022.pdf. Acesso em 13/09/2020.

OLIVEIRA, K.; SILVA, M. K. A. Mapeamento das areas de risco a inundação no municipio de Rio Grande da Serra/SP. In: Anais do XIX Simpósio Brasileiro de Sensoriamento Remoto, 2019, Santos. Disponível em https://proceedings.science/sbsr-2019/papers/mapeamento-dasareas-de-risco-a-inundacao-no-municipio-de-rio-grande-da-serra-sp. Acesso em: 26/08/2020.

PFALTZGRAFF, P. A. S. Mapa de suscetibilidade a deslizamentos da região metropolitana de Recife. 2007. Tese de Doutorado. Programa de Pós-Graduação em Geociências, Universidade Federal de Pernambuco, Recife, 2007. Disponível em https://repositorio.ufpe.br/handle/123456789/6331. Acesso em 13/09/2020.

VESTANA, L. R. A importância da hidrologia na prevenção e mitigação de desastres naturais. Ambiência, v. 4, n. 1, p. 151-162, 2008. Disponível em https://revistas.unicentro.br/index.php/ambiencia/article/view/295/1893. Acesso em: 12/09/2020. 